Case Report

\title{
Blue and Green Spaces as Therapeutic Landscapes: Health Effects of Urban Water Canal Areas of Isfahan
}

\author{
Amirafshar Vaeztavakoli ${ }^{1}\left(\mathbb{D}\right.$, Azadeh Lak $^{1}{ }^{1}$ and Tan Yigitcanlar ${ }^{2, *}$ \\ 1 Faculty of Architecture and Urban Planning, Shahid Beheshti University, Tehran 19839-69411, Iran; \\ amirafsharvt@gmail.com (A.V.); a_lak@sbu.ac.ir (A.L.) \\ 2 School of Civil Engineering and Built Environment, Queensland University of Technology, 2 George Street, \\ Brisbane, QLD 4000, Australia \\ * Correspondence: tan.yigitcanlar@qut.edu.au; Tel.: +61-7-3138-2418
}

Received: 22 September 2018; Accepted: 31 October 2018; Published: 2 November 2018

check for updates

\begin{abstract}
Blue and green spaces contribute to the quality of cities in various ways-ranging from providing air corridors and visual amenities to positively affecting public psychological health and wellbeing. Urban blue and green spaces had geopolitical and agricultural functions in the past. These functions are still evident in many cities. They also provide ecological qualities for the surrounding (sub)urban neighborhoods. While in recent decades, many studies have explored the features and characteristics of urban blue and green spaces that are associated with positive health benefits, the healthy lifestyle promoting role of artificial water canals has received little attention. This case report investigates the canals in Isfahan from Iran that branch off from the Zayandeh Rood River and provide blue and green corridors to the city. The aim of this case report study is to explore the health aspects of urban water canals in physical, mental, and social dimensions based on the residents' experiences. The study develops a framework for assessing the quality of therapeutic effect of canals in Isfahan, Iran. The paper employs qualitative content analysis as the methodological approach. In total, 200 people from the residential neighborhoods of the Niasarm Canal participated in semi-structured interviews in early 2018. The results of this research reveal that the canal-with 'upgrade of active life', 'sense of rehabilitation, relaxation and concentration along with the canal', 'promotion of social life', and 'place identity' characteristics-plays an important therapeutic role on the physical, psychological, and social health conditions of local residents.
\end{abstract}

Keywords: blue space; green space; therapeutic landscape; public health; water canal; urban sustainability; Isfahan; Iran

\section{Introduction}

The World Health Organization (WHO) defines human health as the state of entire physical, psychological, and social welfare, not just the absence of disease or debility [1]. Natural environments are increasingly seen as the basis for urban health promotion [2-4]. It is thought that a healthy ecosystem is an environment that is devoid of confusion and degradation, maintains its own organization and independence, and is flexible to stress [5-8]. Epidemiological studies revealed a positive relationship between longevity and access to green spaces $[9,10]$, and between green spaces and health [2,11]. Similarly, urban blue spaces-including all the surface waters of a city-also play a vital role in health promotion [12]. The concept of public health includes various physical, mental, and social factors, where urban blue and green spaces have a positive impact on them [13]. For instance, in terms of physical health, urban blue and green spaces provide opportunities for physical exercise and recreation activities that increase an individual's wellbeing [14-16]. As for mental health, blue and green spaces improve emotional state and reduce the stress level of individuals [15]. In terms of social 
health, blue and green spaces promote social interaction of an individual and create pleasant collective memories of presence in nature [17].

Despite the literature on blue and green spaces is being extended, the topic of the health-promoting role of artificial urban water canals in their neighborhoods is understudied [12]. This case report, hence, places an urban blue and green corridor under the microscope to explore its health aspects in physical, mental, and social dimensions from the angle of the residents' perspectives. The Niasarm Canal-that is an artificial branch of the Zayandeh Rood River and an urban blue and green corridor of Isfahan, Iran-is selected for this investigation.

The Zayandeh Rood River in Isfahan, a city in the center of the Iranian plateau with hot and semi-dry warm weather, is one of the most important rivers of Iran. One of the well-known traditional methods of transporting the river's water to the surrounding farms, gardens, and neighborhoods in Isfahan is called the canal network (so-called 'Madi' in the local context). This artificial canal network in Isfahan is a significant urban element for the city as it highly influenced the architecture, urban form, design, and structure of Isfahan. This water transportation network is a result of the urban design practices during the Safavid Dynasty (1501-1722). Besides enabling water distribution and shaping the urban fabric in Isfahan, it also played an important role in the development of the Safavid Garden City of Isfahan [18]. Traditionally, the canal network's main function was to transfer water, where this performance today has become less important [18]. At present, the canal network plays a greater role in providing recreative activities to the residents and visitors.

This case report investigates the contribution of the Niasarm Canal as blue and green spaces and also as therapeutic landscapes to its surrounding neighborhoods in Isfahan. The paper concentrates on addressing the research questions of 'whether the canal contributes to the improvement of residents' health and wellbeing as a therapeutic landscape' and 'if so, which characteristics of the canal matter most for the healing effect'. This research applies qualitative methods of interviews with the residents and content analysis of the transcriptions to examine the therapeutic effect of the canal-improving active life, sense of relaxation, rehabilitation, concentration, social life, and place identity.

\section{Materials and Methods}

\subsection{Literature Review}

The concept of a therapeutic landscape was first introduced in 1992 by Gesler [19] as a way of examining why certain environments seem to help the 'healing sense of the place' $[19,20]$. This conceptualization reflected the significance of comprehending the physical and social health promoting aspects of a given space as well as emotional features in urban environments [21]. Shortly after, scholars expanded the concept to bind the health-promoting, as well as healing, properties of therapeutic spaces and the therapeutic value of everyday spaces [22]. These contained both aesthetic properties and more unperceivable social networks $[23,24]$. Health dimensions of the therapeutic landscape in the types of blue and green spaces are defined by Finlay [13] as physical, mental, and social health.

There are several incidental reflections of blue space within the green: in rivers, lakes, and coasts [25], and many studies available evaluate the health effects of exposure to green/blue spaces [26]. Research findings confirm beneficial effects of surrounding greenness were observed in buffers of even $3 \mathrm{~km}$ or areas above $5 \mathrm{~km}^{2}[2,27,28]$. In health geography and environmental psychology, substantial research on green spaces demonstrates their potential to promote health and wellbeing [29]. Green spaces as the elements of the therapeutic landscape play an important role in increasing the quality of air and eliminating harmful gases and pollution [30]. Green spaces can be effective in reducing anxiety and social stress [31]. For instance, students who are stressed about their exams can reduce their stress levels by having a nature walk and observing animals and plants [32]. Research shows that employees who are able to view natural landscapes from their office have better performance [33]. Plants can reduce ammonia $\left(\mathrm{NH}_{3}\right)$, carbon dioxide $\left(\mathrm{CO}_{2}\right)$, nitrogen oxides $\left(\mathrm{NO}_{\mathrm{x}}\right)$, suspended particles, and sulfur dioxide $\left(\mathrm{SO}_{2}\right)$ [34]. In populated urban spaces, the presence 
of green spaces can play a positive role in increasing the mood of people to fight poverty and life problems [35]. Besides, the green infrastructure maintains water resources as well as the sustainability of the environment that contribute to the wellbeing and quality of communities' life [36-39].

Blue spaces cover all levels of the city where water exists or is flowing [12]. Three cross-sectional studies evaluated the mental health advantages of blue spaces $[2,40,41]$. The first study confirmed that the proportion of urban blue spaces in buffers of 1 and $3 \mathrm{~km}$ is not associated with mental health [2]. The second study showed that living less than $5 \mathrm{~km}$ from the coast improved mental health (measured with the general health questionnaires) compared to living further away, even after adjusting for a percentage of green space and fresh water [40]. The third study did not observe associations between the presence of blue spaces (within buffers ranging from 100 to $1000 \mathrm{~m}$ ) and mental health [41]. By healthy blue space, we mean health-enabling places and spaces, where water is at the center of a range of environments with significant potential for the promotion of human wellbeing'. The term blue demonstrates its established associations with oceans, seas, lakes, rivers, and other bodies of water [42]. Relationships between the body, health, and place are remarkable in culturally shaped health geographies $[43,44]$.

The impact of enormous blue spaces such as the oceans on health has been discovered recently $[40,45]$. Likewise, blue spaces offer versatile and popular places for physical activity. These activities comprise on the one hand water-specific sport and leisure activities such as bathing, swimming, paddling, sailing, fishing, and on the other hand, associated activities such as walking, running, biking, and skating by water [46]. Research has shown that blue spaces are the best option for rest and relaxation among people $[47,48]$. Besides, it is believed that with the presence of families on the beach, in addition to their physical and mental health, their social health has also been positively impacted [49]. Additionally, studying the sound of the surroundings showed that blue spaces, such as rivers and fountains, were the best means of covering the traffic noise [50,51]. Moreover, a study by Voelker [52] showed that blue spaces can moderate the weather during the summer days and the presence of water in green spaces can add to the positive impact of these spaces $[52,53]$. More locally-based urban blue spaces, such as rivers, streams, canals, or ponds, could not be considered in detail in previous studies, but have an underestimated researched potential for human health in the urban context, not least in terms of scale [13].

Specific urban blue spaces, such as streams, ponds, or canals, were not the focus of much of the previous studies. Particularly urban water canals is an understudied research area given their potential for human health in the urban context [13]. Urban water canals consist of two types. The first one is the natural streams, 'a body of flowing water'; and the second one is the artificial canals, 'an artificial open waterway constructed to transport water, to irrigate or drain land, to connect two or more bodies of water, or to serve as a waterway for watercraft' $[54,55]$. The study reported in this paper concentrates on the latter.

\subsection{Case Study}

The Niasarm Canal is selected as the case study (Figure 1). This is due to the following reasons: This canal is one of the largest most vital canals in Isfahan. It is branched near Marnan Bridge, passes Lanban district and goes towards the east of the city. This canal area has the most water and green space among other canals in the city. The canal is the nearest to Zayande Rood River and almost runs parallel with it in the north of that river from west to east of the old city [18]. At present, the Niasarm Canal is the most popular blue and green space in Isfahan-as it has various active and passive green areas around the canal (Figure 2). The canal, which is one of the largest canals in Isfahan, is branched near the Marnan Bridge and goes towards the east of the city [18]. Looking the land use allocation in the surrounding neighborhoods revealed that residential areas are the most dominant land functions of the area (Figure 3). The most important commercial uses are located at the intersection of the Niasarm Canal and Charbagh Street-the main historic street of Isfahan (Figure 4). 


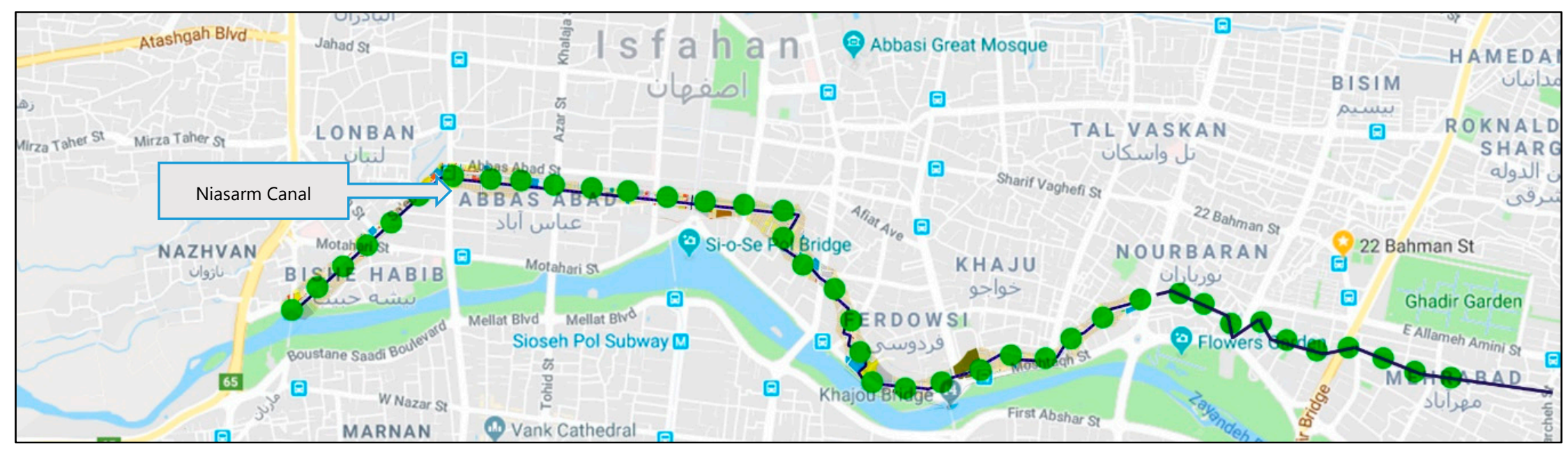

Figure 1. Niasarm canal in Isfahan.

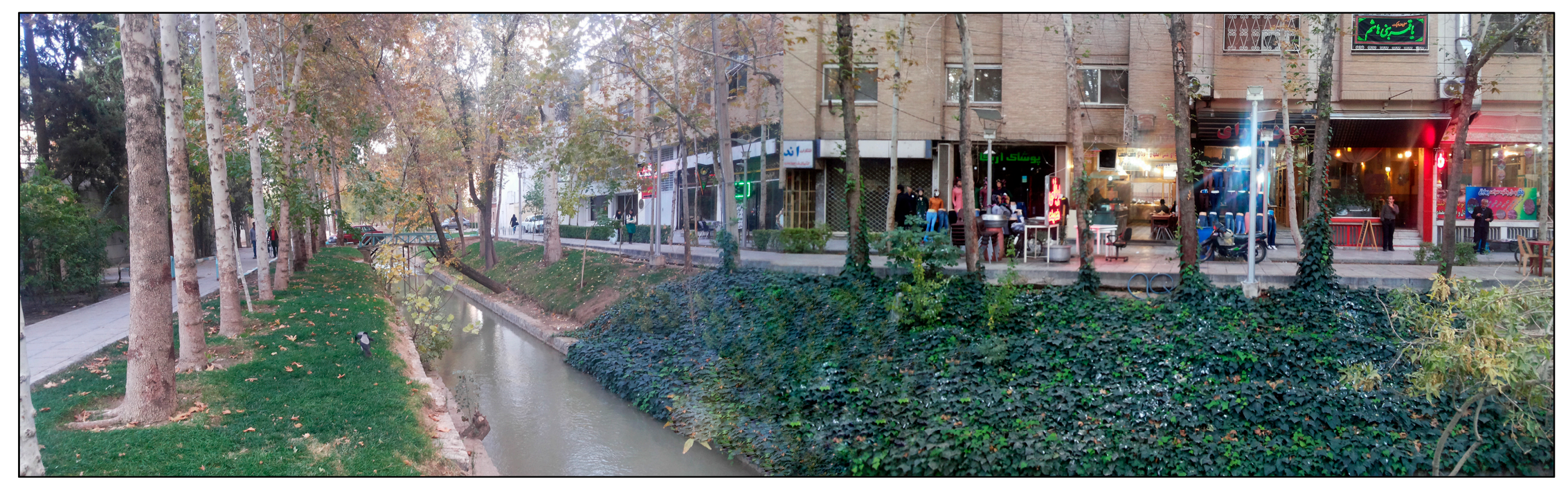

Figure 2. Plant diversity and related activities in the canal. 


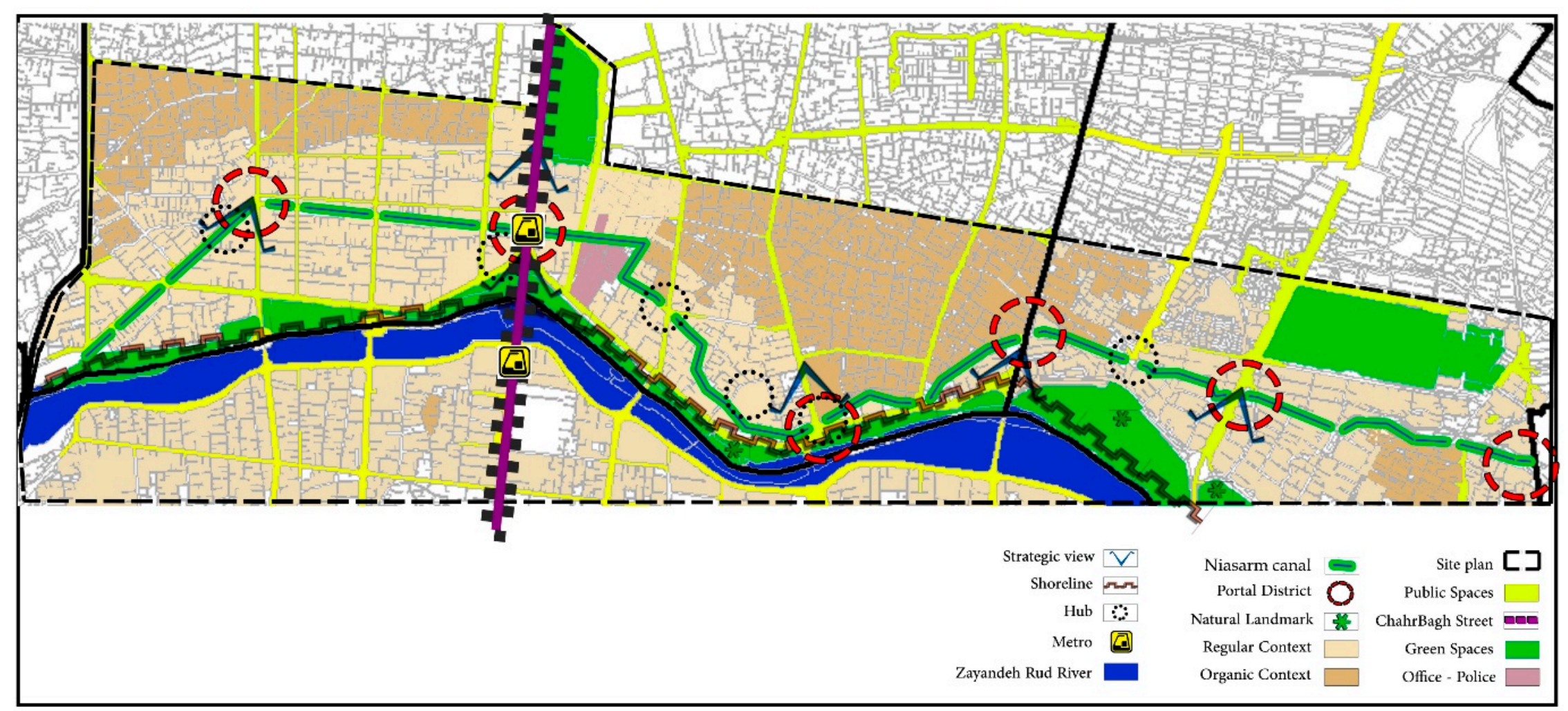

Figure 3. Location of the study area 


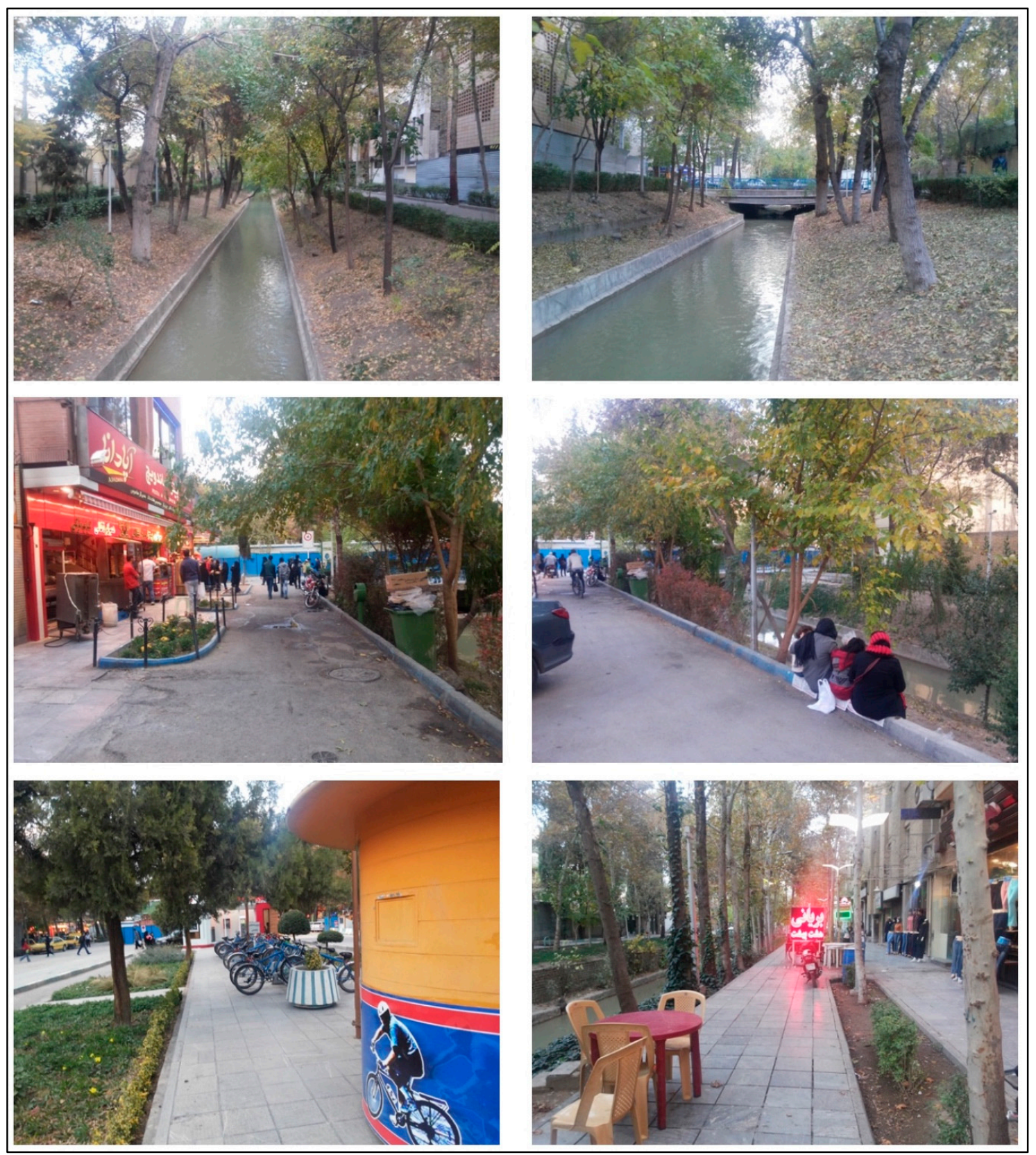

Figure 4. Photos from the study area.

Being a highly attractive area for visitors and tourists and having a good pedestrian network, the canal area is one of the most desirable places to walk in Isfahan. On the other hand, the underground station that is in close proximity to the canal facilitates easy access to the area from the rest of the city. The wide variety of plants and the flow of water in the canal creates fresh air and breeze. Subsequently, in summertime the temperature difference in the canal and the rest of the urban environments is quite noticeable - the air temperature is about two to three Celsius degrees cooler around the canal [18].

\subsection{Method and Data Collection}

To cover the therapeutic landscape dimensions (physical, social, and mental), a survey questionnaire with open-ended questions was prepared. The survey was undertaken as a face-to-face interview with the local residents-due to no secondary data available on the topic. The survey was designed including questions on age, the frequency of using the canal, education, gender, and 
socio-demographic status of the participants and so on (Appendix A). The questionnaire was prepared based on previous studies that investigated the impact of the natural environment on public health, to name a few [12,13]. During April 2018, a pilot survey was conducted to test the adequateness of questionnaire and received responses. In total, 10 participants were interviewed in different parts of the Niasarm Canal (e.g., at the entrances, at benches, on lawns, and so on), while they were engaged in a variety of activities (e.g., sitting, cycling, walking, jogging). The respondents were asked to answer whether they wanted to spend their time at the Niasarm Canal in a blue and green space. All interviews were conducted in Persian language, digitally recorded, transcribed manually, and translated into English language. The results of the pilot survey were found satisfactory and without any major changes the questionnaire was directed to 200 respondents.

The length of completing a questionnaire ranged between 15 and $20 \mathrm{~min}$. In total 200 people were interviewed until theoretical saturation. This study is qualitative and surveys were continued up to theoretical saturation. Theoretical saturation of data means that researchers reach a point in their analysis of data that sampling more data will not lead to more information related to their research questions [56]. Different from the pilot survey exercise, at the survey study questionnaires were completed with face-to-face interaction at the doorsteps of the surveyed residents. All three surrounding neighborhoods of the canal were targeted in the survey (Figure 5). By using systematic random sample method interviewees were selected in almost equal numbers from each neighborhood. The number of participants in three neighborhoods was: 68 from neighborhood 1 (Bisheh Habib), 67 from neighborhood 2 (Abbas Abad); 65 from neighborhood 3 (Charkhab). Pilot survey responses $(n=10)$ were not included in the study in order to not to provide any bias-such as those that are already using or benefiting from the canal reflecting their views rather than people representative of general community in the neighboring areas of the canal.

Research synopsis and identity privacy issue were presented verbally prior to the survey to the participants. To ensure participant confidentiality and anonymity, no identifying information was recorded-besides the address. The salient socio-demographic characteristics of the interviewees are listed in Table 1. The age of interviewees ranged between 15 and 85 years. In addition to the survey data, spatial data is also collected and analyzed via a geographic information system (GIS) platform, as GIS-based analyses have become a popular approach for health planning during the recent years [57]. Hence, this study also undertook such analyses as well (Figure 5). The canal area is mostly surrounded by residential uses, however, there are also some commercial (mostly retail) establishments in the western part of the canal. The eastern part of the canal contains more housing units in higher densities.

Table 1. Socio-demographic characteristics of the interviewees.

\begin{tabular}{cccccc}
\hline Gender & Count & Age Group & Count & Education & Count \\
\hline Female & 102 & $15-35$ & 18 & Primary & 36 \\
& & $36-45$ & 60 & Secondary & 55 \\
& $46-65$ & 19 & Tertiary & 11 \\
& & $65-85$ & 5 & & \\
\hline Male & 98 & $15-35$ & 17 & Primary & 24 \\
& & $36-45$ & 40 & Secondary & 60 \\
& & $46-65$ & 32 & Tertiary & 14 \\
& & $65-85$ & 9 & & 200 \\
\hline
\end{tabular}




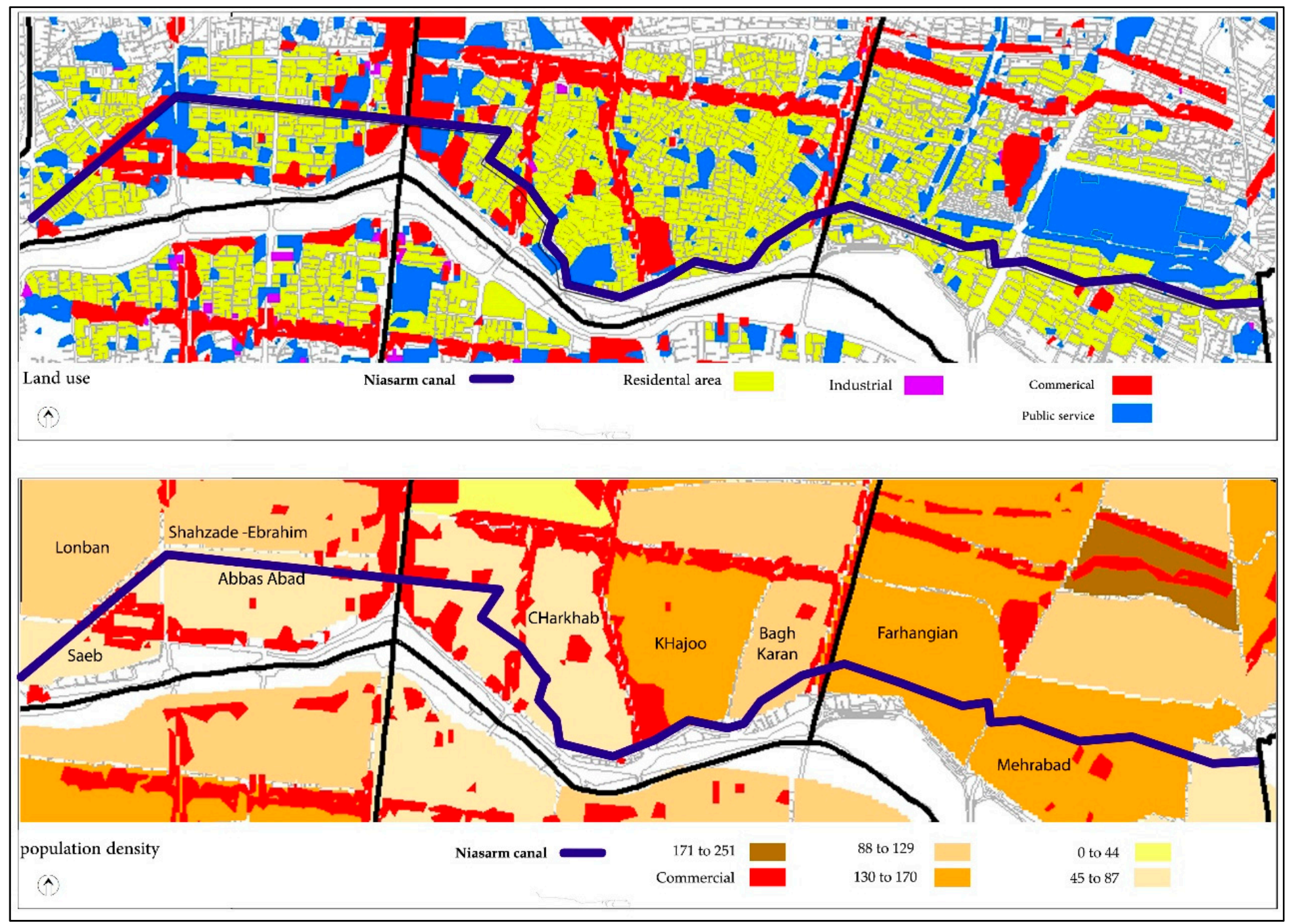

Figure 5. Land use and the population density (ppl/ha) of the study area. 


\subsection{Data Analysis}

The qualitatively collected data were organized and transcribed. The transcripts were reviewed using the dimensions of health to describe, interpret and analysis by content analysis. Before data analysis, control steps were exactly set in analogy to Flick [58] and Völker and Kistemann [12]. The descriptive statistics of the survey data is presented in Table 2 in the results section of the paper. The interviews were analyzed according to the following aggregation scheme: Firstly, the responses were reduced to their core statements by means of a content analysis, and thus produced a reduced corpus. Then, the key points were assigned to higher-level dimensions and codes, thus the individual interviews and data could be compared with each other. Codes and their combinations were weighted according to frequency and interrelations. By using a frequency analysis of statements in each dimension and codes, we were able to analyze the subjects' intersubjective perception of core and edge regions. Lastly, an aggregated structure was constructed, which displayed the prevailing dimensions and codes in the research areas [9]. All the concepts and codes were adopted by the constant comparison method to compare and contrast themes within and across groups to achieve similarities and differences in the gathering data [59]. A total of 54 concepts and 11 codes were identified and presented in Table 3 in the results section of the paper. Following this, the following four main themes were determined:

- Theme 1: Canal's importance in promoting active life;

- Theme 2: Sense of rehabilitation, calmness, and concentration alongside the canal;

- Theme 3: Canal as the core of social life in neighborhoods;

- Theme 4: Place identity and cultural heritage.

This research used a number of strategies to reinforce the rigor of the study. These included: reflexive memoing throughout the data gathering and analysis process, extracting the concepts and codes from other experts, and the overall story created by researchers and participants [12].

\section{Results}

The study employed a qualitative approach to analyze the collected data. However, a descriptive analysis—with simple descriptive statistics containing basic measures to describe the survey data-is presented in Table 2.

Table 2. Simple descriptive statistics of the survey data.

\begin{tabular}{cccc}
\hline Characteristic & Frequency & Unit & $\%$ \\
\hline Total participant population & 200 & People & 100 \\
Female participants & 102 & People & 51 \\
Male participants & 98 & People & 49 \\
Age of participants (median) & 37 & People & - \\
Education level of participants (median) & Secondary & School & - \\
Income level of participants (median) & Medium-low & Income group & - \\
Park visit frequency of participants (median) & Every 3 & Days & - \\
Time spent in each park visits by participants (median) & $45-60$ & Minutes & - \\
Contributions to feel healthier and/or happier (yes) & 158 & Response: Yes & 79 \\
Contributions to physical health (yes) & 124 & Response: Yes & 62 \\
Contributions to mental health (yes) & 128 & Response: Yes & 64 \\
Contributions to social activities (yes) & 130 & Response: Yes & 65 \\
Contributions to life (yes) & 182 & Response: Yes & 91 \\
Contributions to local community (yes) & 124 & Response: Yes & 62 \\
Encourage others to visit the canal (yes) & 178 & Response: Yes & 89 \\
\hline
\end{tabular}

This study focused on the effects of canals as urban blue and green spaces on humans' health and tried to extract relevant concepts (Table 3). All concepts have been extracted from the content analysis process of transcribed surveys. According to the frequency of repetition concepts, the codes and categories were categorized through the health dimensions. Firstly, the participants widely believed 
that the canal helps them to have a more active life through walking and doing exercises in the blue and green spaces, because of the fresh air and relaxed atmosphere. They also mentioned different roles of canals in promoting their active lifestyles. Secondly, the survey findings highlighted the sense of rehabilitation, calmness, and concentration alongside the canal. This means that people are more relaxed and feel better while using these blue and green spaces. In other words, participants have a consensus on that they are quite consistently associated with greater benefits in terms of positive emotions and psychological states as a result of being in touch with the blue and green space of the Niasarm Canal.

Table 3. Perspectives of the participants.

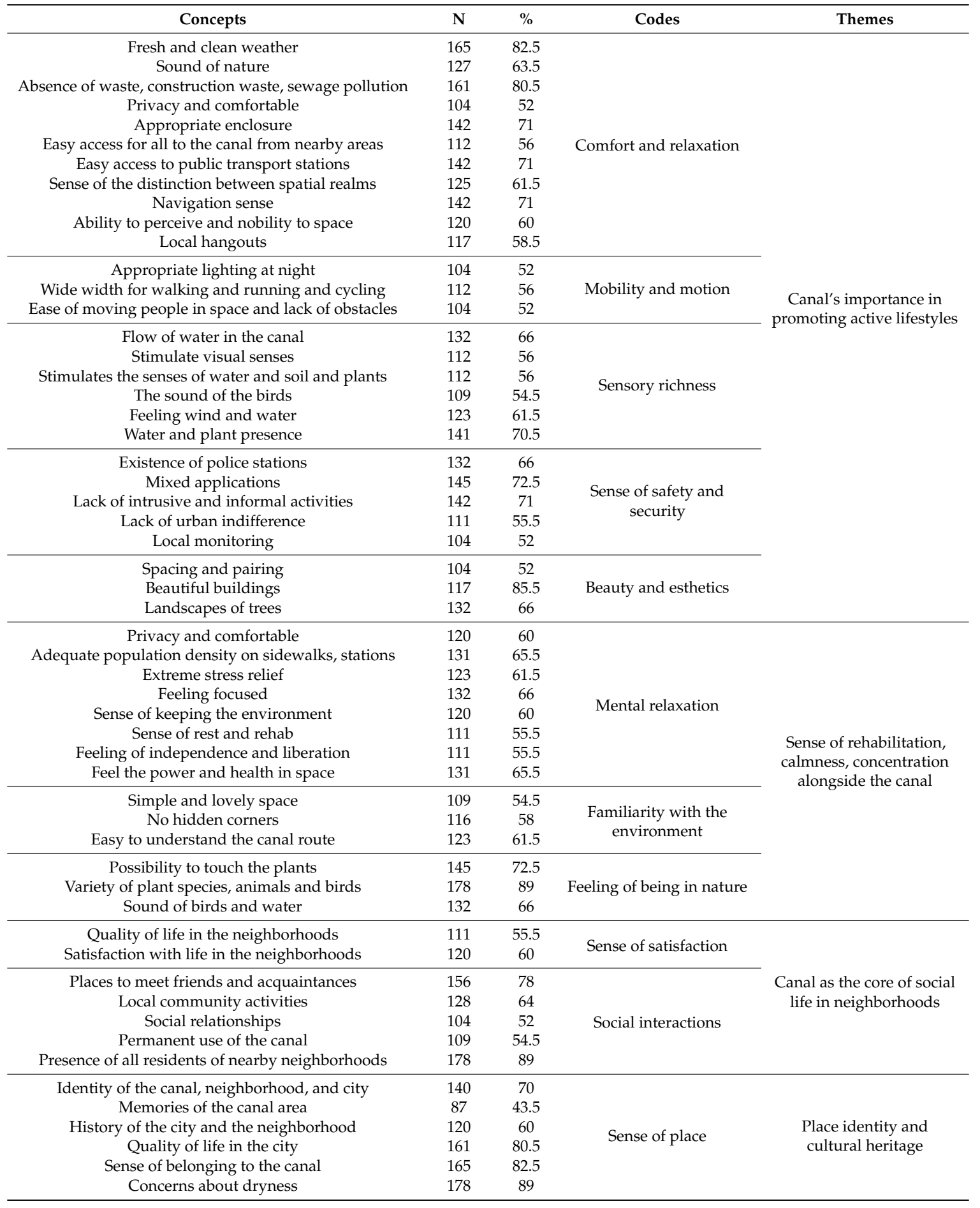


Additionally, participants claimed that they see the canal as the core of their social life in their neighborhoods. The majority of participants prefer to meet their friends and relatives near the canal, which increases social interactions in local communities, and the canal has an important cultural and spiritual value for them. Lastly, surprisingly, participants highlighted another feature of the canal that make them feel healthier-'place identity and cultural heritage of the canal in Isfahan'. The study finds that the Niasarm Canal has cultural and spiritual value for many people in the area and the canal was expressed as the symbol of place identity for the residents. Locals admired the canal as a significant contribution of cultural heritage to their neighborhoods and Isfahan.

All concepts, codes, and categories are presented in Table 3. These concepts and codes are identified as the key influences of the canal, based on participants' sense of healing in physical, mental, and social wellbeing. However, the survey also captured some of the negative or undesirable aspects of the canal as well. For instance, the seasonality of the canal's water levels is a challenge. Especially during the hot summer days, the canal goes fully dry. These are the days that locals willing to go near waterbodies the most. The drought is to blame but surely the courses of this environmental phenomenon also relates to human impacts on the environment-the age of Anthropocene [54]. Another issue is the canal at times being a mosquito-breeding ground, particularly due to slow flow or pooling conditions. While municipal spraying (using trucks to spray a community at night) could be a temporary solution, this effort contributes to the air and water pollution.

The respondents also raised the issue of the canal and surrounding area being subjected to littering by the users, businesses, and even passer-by vehicles. Especially when the poor management of the canal and its surrounding green space is added on to that issue, the problem multiplies. Lastly, in most parts of the canal area the width of the green space, at both sides of the blue space, does not go beyond a couple of meters. Especially when the slope of the green space is considered in most of the canal area active green areas are limited and also creates hazard (see Figures 2 and 4). While there are some nearby green spaces in the surrounding areas, there is only limited direct pedestrian connectivity between some of them and the canal (see Figure 3).

The following sub-section elaborate the four themes formed during the content analysis (Table 3), namely: (a) Canal's importance in promoting active lifestyles; (b) Sense of rehabilitation, calmness, concentration alongside the canal; (c) Canal as the core of social life in neighborhoods; (d) Place identity and cultural heritage.

\subsection{Canal's Importance in Promoting Activities in Everyday Life}

The study at hand revealed that increasing physical activity in the daily life of the participants is the most important factor that the majority of participants referred to as the canal's impact on their desire to walk and exercise more. Activities such as walking, running, and morning exercise are the most important activities that all the participants from all age and gender groups refer to. For example, this issue was brought to the conversation as:

"The canal in every street is a park for my daily walk; firstly, it is near my house, also it has a direct and green route that encourages me to walk." (a 57-year-old woman)

"Canal corridors can provide opportunities for recreation as part of daily life allowing stress relief and enjoyment as well as activities such as walking, cycling and exercise. However, when the canal runs dry we feel sad." (a 25-year-old woman)

Most participants have chosen the canal path for easy walking. Fresh air, clean place, the sense of territory, and easy access from home to the canal are all the features that participants point to as the canal's options that ultimately help to improve their daily activity. Contributions to healthy lifestyles and sustainability of the neighborhoods-both in terms of environmental and social-have been also highlighted. For instance, it is remarked as:

"Where do I find better than the canal for walking? fresh air, usually cooler than the alleys, it is the best place to walk and makes you feel healthier." (a 67-year-old man) 
Moreover, the sense of safety and security alongside the canal was mentioned. According to the absence of abandoned spaces, the presence of residents, suitable path for walking and night lighting, the right width for walking are decisive factors to increase physical activity in the form of walking and daily exercise of local residents in the canal. For example, the safety issue is put forward as:

"The canal is the best path to walk, because it is safe and uninterrupted, and it does not feel unsafe walking along its path in the afternoons." (a 35-year-old woman)

Another feature that participants pointed to in is the pleasant outdoor landscape resulting from the formation of a green valley-continuous green corridor, even at times very narrow. Beautiful old trees and the sense of green space help to increase physical activity and an active life alongside the canal for its residents. Besides, other factors, such as vitality and sensory environmental richness, along with increasing the sense of wayfinding or visual-physical permeability have contributed to the physical and mental health and wellbeing of the residents.

On the other hand, a few people were really worried about preserving the environment of the water canal. They believed that some waste generated in the process of constructions near the canal or sewage pollution can be a serious problem. They also mentioned that being near the canal during the spring and summer is a great experience, but pesky mosquitoes can sometimes make it feel more like a nightmare. Their annoying buzzing and biting can ruin a perfectly planned day. The local authority complained that they lacked sufficient financial resources to improve the situation. For instance, this negative aspect was criticized as:

"Water can be a breeding zone for pesky insects and other animals. Mosquitoes can be a major nuisance, depending on location and time of the day." (a 31-year-old man)

\subsection{A Sense of Restoration, Relaxation, and Concentration in the Canal}

This study disclosed that increasing green and blue spaces of the canal have the most impact on the sense of concentration, tranquility, and recovery. This sense of mental relaxation is due to the qualities such as adequate personal territory, spacious space, relaxed atmosphere, great sense of concentration and independence, and the sense of rejuvenation and emancipation from the stress. For example, it is highlighted that:

"When I come into this atmosphere, I feel that I can easily focus on subjects, looking at trees and it makes me relieved." (a 42-year-old woman)

Participants have referred to the sense of being close to the water, the flying leaves in the wind, the smell of water, as well as a sense of escape from the urban environment. The unity of water and plants and the sense of ownership and coherence in the environment are all important in feeling comfort for the participants, as well as the sense of familiarity and legibility. According to the participants, being near the water and plants of the canal is another feature that plays a vital role in having a sense of tranquility, and gives residents a 'sense of home'. For instance, it is mentioned that:

"The sound of water at times when the canal has high water levels makes me feel relaxed and happy."

(a 70-year-old woman)

"When I spend time at the canal, it makes me feel relieved from my daily life and helps me to escape from economic and social stresses I go through." (a 45-year-old man)

\subsection{Canal as the Core of Social Life in Neighborhoods}

The study at hand revealed the significance of the canal for the social life of the locale. The majority of participants acknowledged that the canal creates the best place to be together in community. According to participants, the canal has been used as a recreational space for relatives and friends and still, a lot of local visits and meetings are alongside the canal. For example, a participant highlighted that: 
"We have spent our family vocation alongside the canal, and we still continue to come together in the canal annually, even when the canal does not have water in the summer." (a 62-year-old woman)

The participants consider the canal as a space for the presence of all social groups. Women feel the security, safety, and locality. Children are easily under the control of their parents, and elderly people enjoy the safety and security. Men play the backgammon game with their friends. It is also stated that:

"When the weather is good, the canal is full of people from the neighborhood. Women, children, and old people all prefer to socialize together alongside the canal." (a 45-years-old man)

The presence of neighborhood events alongside the canal is another factor in helping people's sense of community and the participants' satisfaction with the canal. Participants claim that social relationships between residents, friends, and acquaintances in the neighborhood are facilitated because of the canal. Thus, the canal also plays the role of social lubricant.

\subsection{Place Identity and Cultural Heritage}

This study disclosed that most of the participants in this study are proud of the canal in their neighborhood. They consider the canal as the identity of their residence and as a symbol of their cultural values, which contains personal and social memories of local ceremonies. The existence of memories is the specific canal's quality that distinguishes the identity of neighborhoods within the canal from other neighborhoods. It also can lead to the formation of emotional attachment to the canal environment that is a sense of pride and satisfaction with life by the canal. For example, this issue was elaborated as:

"This canal revives good childhood memories for me, whenever I sit next to the water, I become young again and I feel euphoric." (an 82-year-old man)

"Everyone has a really strong empathy with water and the canal and its history and its current environment, but we are worried about the poor management of this water canal." (an 80-year-old man)

\section{Discussion}

The findings of this research-reported in the results section-are comparable with the findings of Völker and Kistemann's [12] research results, which explored the blue and green environment health effects in the form of emotional bonding, participation, and physical activity. Besides this, another study conducted in Canada on the effects of the therapeutic landscape for the elderly people focusing on the influenced participant perceptions on their physical, mental, and social health conditions also reveals similar findings [13]. It should be noted that most of these studies also employed similar qualitative research and analysis techniques [12,13].

Previous studies reported in the literature also highlighted the health effects of physical activity in the green and blue environment $[2,12,13]$. Increased physical activity, resulting from feeling comfortable, suitable urban furniture, adequate lighting, the presence of trees, and fresh and clean air can lead to physical health [12]. In addition, the environment has been influenced by the coherence of the blue and green spaces and the quality of the built environment along with the canal. Previous studies also emphasized the effects of the built environment on increasing physical activity [59]. Being safe and secure, with the sense of navigation, vitality, and the lack of vagueness are also the factors that have encouraged participants to have more active lifestyle such as walking, jogging, and biking along with the Niasarm canal. The study of Ghalehnoee and Alikhani's [60] research showed parallel results. In their study, the Niasarm Canal as a green infrastructure is known as a path in the city of Isfahan that provides the walkability with safety, and residents' comfort [60].

In terms of mental health, the canal environment has been able to provide a relaxed atmosphere, with a sense of concentration, thoughtfulness, rehabilitation, and rejuvenation. For participants, the available green and blue space of the canal provides a unique freedom that ultimately leads to a 
feeling of emancipation. It is believed that the natural environment can provide a sense of pleasure and enjoyment, relaxation, freedom, and rehabilitation [13,61,62]. Moreover, green space creates an opportunity for escaping from the daily life and can reduce anxiety [13]. The study of Ghalehnoee and Alikhani [60] examined the cheerfulness of space and the sense of living with nature in the canal, which mentioned as a positive feature. Furthermore, the canal gives residents a sense of home, and in this way, they also feel relaxed and comfortable. According to social health, also the Niasarm canal is well-known as a place for social interactions. The canal is considered as the second home of the residents for their social life, social interactions and communicating with neighbors. Besides, many neighborhood events have been taking place alongside the canal.

In addition, the presence of different age and gender groups in the green and blue space of the canal as an inclusive space is noticeable in the neighborhoods. Earlier conducted studies pointed out the social role of green space in forming social relationships through the presence of blue space $[12,13,63,64]$. They also have confirmed that public spaces allow increasing interaction through observation, communication or behavior, as well as the leisure activity [65]. In this respect, in addition to urban green, the urban blue spaces provide successful public places in the overall urban fabric to attract people [12]. This study reveals that the canal's users are more likely to interact with friends, relatives, and neighbors than strangers. Völker and Kistemann [12] also confirmed that people in the green environment tend to have a sense of being alone and socializing with acquaintances than communicating with others.

The study by Ghalehnoee and Alikhani [60] emphasized the lack of facilities and amenities in the canal, which reduced the possibility of gathering and participating in space. Eventually, the canal improved the sense of identity of the inhabitants by becoming a symbol of the city of Isfahan and its neighborhoods. Residents of the neighborhoods have established a special emotional relationship with the canal's environment and accepted the canal as a part of their home. The sense of place and place identity are the influential factors of the canal, and the connection of neighborhoods with the Niasarm canal makes these neighborhoods popular in Isfahan. This sense of pride helps them feel better about their lives. The sense of belonging can be effective in improving the health of individuals $[12,66,67]$. The historical role of the canal, the presence of collective memories, and concerns about the possibility of the canal's dryness all reflect the sense of belonging to the canal, which ultimately can affect the mental health of the inhabitants. The feeling of pleasure and satisfaction of life along with the canal is effective in the perception of health in residents.

Furthermore, this study revealed that water scarcity and drought are two of the main concerns of residents about the Niasarm canal and those factors may transform the canal into a waste disposal site. Hence, assessing the environmental features of an integration of water and plants, applying integrated urban water management including water sensitive urban design principles are important not only to improve the health of residents, but also for the entire natural ecosystem of the study area [68-70]. The local authority should make all necessary efforts to improve the quality of the canal as the study disclosed it has implications on the health and wellbeing of the residents. Especially this issue of effective urban management becomes a more critical at the dawn of catastrophic climate change impacts—-both socioeconomic and environmental [71-73].

In the light of the investigation and findings, this study also developed a framework of the canal as a therapeutic landscape (Figure 6). This framework could serve as a guide for further investigations on the contributions of blue and green spaces in the context of an urban canal to the health and wellbeing of local residents. The framework highlights the effects of canals on humans' health consisting of four dimensions (Figure 6). Firstly, canals play a vital role in promoting active life by encouraging people to be present in blue spaces. Secondly, canals are the fantastic places that make people feel relaxed and restored. Thirdly, canals in Isfahan are the core of social life in neighborhoods and set the stage for social interactions and satisfaction. Lastly, canals in Isfahan are the important symbol of cultural heritage and enhance people's sense of identity. 


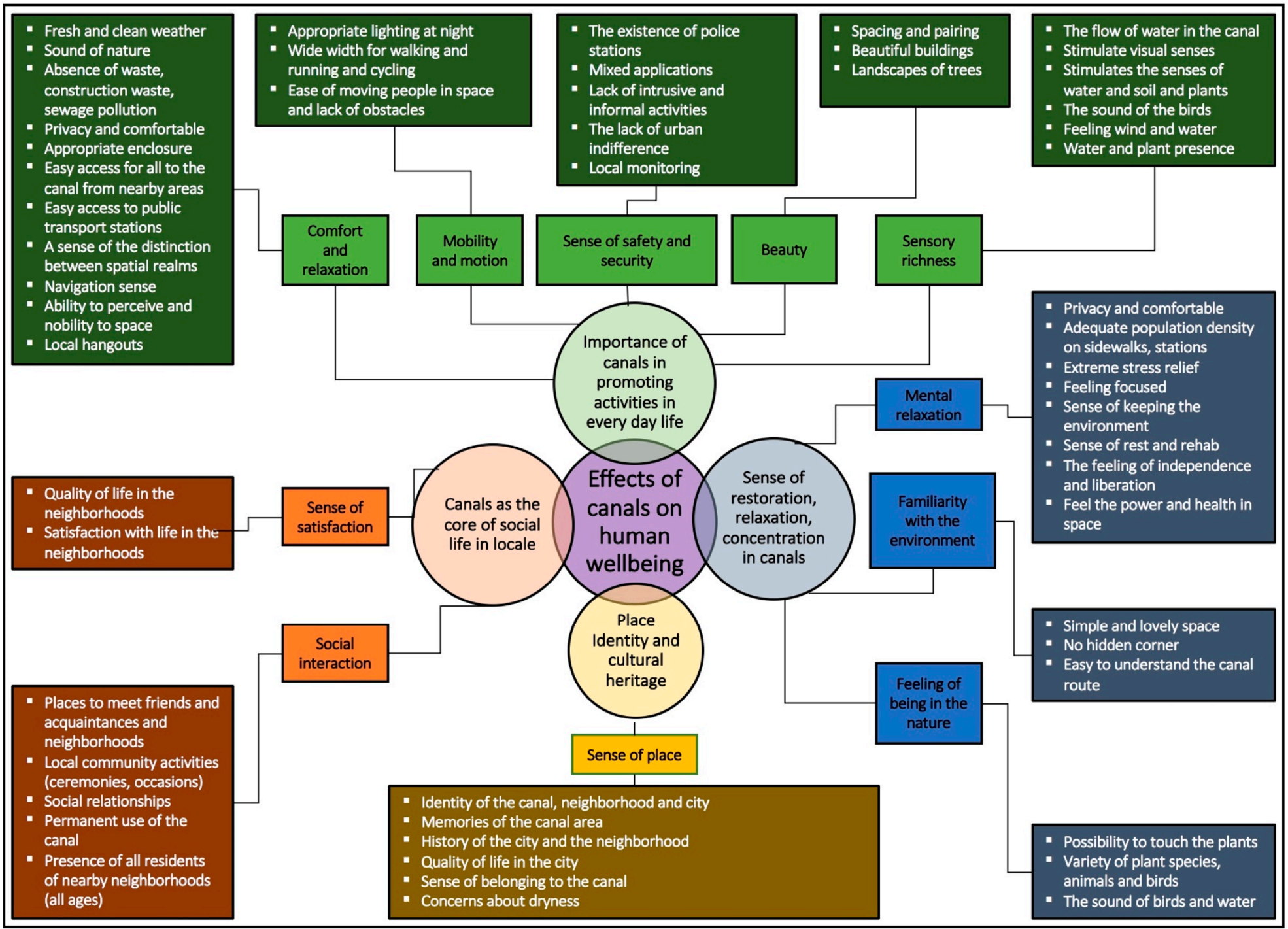

Figure 6. A framework of the canal as a therapeutic landscape. 
Lastly, we advocate that the health planning practice shall be an integral part of the urban planning and design practice in cities that are fortunate to have both blue and green spaces. This is to say the disconnect between urban planning and public health should be bridged. On that very point, Cornburn [74] highlights that "reconnecting public health with planning will require the fields to embrace their physical and social dimensions, address health disparities burdening urban populations, and democratize research and decision-making practices. Although the task is daunting, insights from both fields might assist in the effort. In public health, social epidemiology, particularly ecosocial epidemiology, provides an interdisciplinary, multilevel perspective for understanding the health status of, and health disparities in, populations. In planning, environmental justice provides a framework for ensuring that decision-making processes and outcomes are democratic and fair".

\section{Conclusions}

The research in the fields of environmental psychology and landscape architecture demonstrates that humans have an innate preference for natural and water settings [75]. The recent health literature also specifies urban blue and green spaces as crucial urban elements that offer therapeutic landscapes to their residents and visitors $[12,13,25]$. This paper investigated the therapeutic and healing attributes of a type of blue and green space- urban water canals-in the case of the Niasarm Canal in its neighborhoods from Isfahan, Iran. The contribution of the study to the knowledge, literature and planning practice takes in several forms.

Firstly, this paper is one of the first published studies placing urban water canals under the microscope to evaluate their health effects on the residents. As a result of a qualitative investigation, the study identified four main themes (Table 3) relating to the attributes and qualities of the therapeutic landscape that affect people's wellbeing. These are: (a) Canal's importance in promoting active life; (b) Sense of rehabilitation, calmness, and concentration alongside the canal; (c) Canal as the core of social life in neighborhoods; (d) Place identity and cultural heritage. The investigation around these four themes revealed that canals of Isfahan as blue and green spaces are vital elements of the city that play an important role in promoting public health. This role is substantial in the physical, social and psychological dimensions of health.

Secondly, this study proposed a framework that depicts the canal as a therapeutic landscape and highlights its key attributes (Figure 6). Although this framework was specifically developed for the Niasarm Canal of Isfahan to improve the health of the residents, it can be generalized in all the neighborhoods that the canals pass through them in the city and also beyond. This is to say with some local ground-truthing work and customization, the framework can be considered for other localities. The framework could be a starting point for Isfahan and other cities with water canals to consider it in their not only urban planning, but also health planning practices.

Thirdly, the study investigates an understudied area and generates directions for prospective research. For instance, although the research findings help in finding a deeper relationship between blue and green spaces, in the context of urban canals and health, the various dimensions of this research can be assessed through prospective studies on the residents of Isfahan (or other cities) - focusing on their health, quality of life, and social capital. However, the following limitations of the study should also be noted: (a) This research identified the role of the canal as a 'therapeutic landscape' from the 'sense of health' and 'general health' perceptions of the residents-rather than using the measured health effects; (b) The analysis conducted is descriptive and qualitative in nature-rather than carrying out thorough statistical elaborations; (c) There might be some possible unintended bias in conducting surveys, the process of data analysis (content analysis) and the method of data collection. Our prospective studies will also focus on addressing these limitations and also conducting further empirical investigations by using both qualitative and quantitative techniques.

Lastly, while in general the positive impacts of the canal are discussed in this paper, it should be noted that surrounding areas of the blue and green spaces could impact the quality of the space both positively and negatively. Particularly in urban areas road and traffic related pollution issues have an 
increasing externality on these blue/green spaces [76,77]. While, it is obvious that a well-maintained urban green and blue area could contribute to the overall sustainability level of the neighborhood both in terms of social and environmental aspects [78-80], in the case of malpractice the otherwise is also correct. This brings the quality of blue/green space issue to the discussion table-quality over quantity. Particularly in Isfahan and specifically in the Niasarm canal area, management of blue/green spaces have not been done adequately. Existence of the surrounding polluting uses and lacking regular maintenance and upkeeping are among the major risks for the quality of the blue/green areas. Addressing these issues will also be the focus of our future research projects.

Author Contributions: A.V. designed the research, collected data, prepared the first draft of the manuscript; A.L. conducted the analysis and contributed to the revision of the manuscript; T.Y. undertook the revisions and language edited the manuscript. All authors have read and approved the final manuscript.

Funding: This research received no external funding.

Conflicts of Interest: The authors declare no conflict of interest.

\section{Appendix A}

Table A1. Survey questions.

\begin{tabular}{ll}
\hline No. & \\
\hline 1 & Age \\
2 & Gender \\
3 & Education level \\
4 & Income level \\
5 & Address (as in neighborhood only) \\
6 & How frequent do you visit the canal? \\
7 & How much time approximately do you spend on each visit? \\
8 & Do you feel healthier and /or happier when spending time alongside the canal? If yes why? \\
9 & Does the canal contribute to improving your physical health? If yes how? \\
10 & Does the canal contribute to improving your mental health? If yes how? \\
11 & Does the canal contribute to improving your social activities? If yes how? \\
12 & What are the contributions of the canal to your life? \\
13 & What are the contributions of the canal to the local community? \\
14 & Do you recommend or encourage others to visit the canal? If yes/no why? \\
15 & Other comments \\
\hline
\end{tabular}

\section{References}

1. World Health Organization (WHO). City Health Profiles: A Review of Progress; World Health Organization (WHO): Geneva, Switzerland, 1998.

2. De Vries, S.; Verheij, R.A.; Groenewegen, P.P.; Spreeuwenberg, P. Natural environments-Healthy environments? An exploratory analysis of the relationship between green space and health. Environ. Plan. A 2003, 35, 1717-1731. [CrossRef]

3. Frumkin, H. Beyond toxicity1: Human health and the natural environment. Am. J. Prev. Med. 2001, 20, 234-240. [CrossRef]

4. Gudes, O.; Kendall, E.; Yigitcanlar, T.; Pathak, V.; Baum, S. Rethinking health planning: A framework for organising information to underpin collaborative health planning. Health Inf. Manag. J. 2010, 39, 18-29. [CrossRef]

5. Costanza, R. Toward an operational definition of ecosystem health. In Ecosystem Health: New Goals for Environmental Management; Island Press: Washington, DC, USA, 1992; pp. 239-269.

6. Lu, F.; Li, Z. A model of ecosystem health and its application. Ecol. Model. 2003, 170, 55-59. [CrossRef]

7. Yigitcanlar, T. Planning for smart urban ecosystems: Information technology applications for capacity building in environmental decision making. Theor. Empir. Res. Urban Manag. 2009, 4, 5-21.

8. Yigitcanlar, T.; Dizdaroglu, D. Ecological approaches in planning for sustainable cities: A review of the literature. Glob. J. Environ. Sci. Manag. 2014, 1, 159-188.

9. Takano, T.; Nakamura, K.; Watanabe, M. Urban residential environments and senior citizens' longevity in megacity areas: The importance of walkable green spaces. J. Epidemiol. Community Health 2002, 56, 913-918. [CrossRef] [PubMed] 
10. Tanaka, A.; Takano, T.; Nakamura, K.; Takeuchi, S. Health levels influenced by urban residential conditions in a megacity-Tokyo. Urban Stud. 1996, 33, 879-894. [CrossRef]

11. Teimouri, R.; Yigitcanlar, T. An approach towards effective ecological planning: Quantitative analysis of urban green space characteristics. Glob. J. Environ. Sci. Manag. 2018, 4, 195-206.

12. Völker, S.; Kistemann, T. Developing the urban blue: Comparative health responses to blue and green urban open spaces in Germany. Health Place 2015, 35, 196-205. [CrossRef] [PubMed]

13. Finlay, J.; Franke, T.; McKay, H.; Sims-Gould, J. Therapeutic landscapes and wellbeing in later life: Impacts of blue and green spaces for older adults. Health Place 2015, 34, 97-106. [CrossRef] [PubMed]

14. Braubach, M.; Egorov, A.; Mudu, P.; Wolf, T.; Thompson, C.W.; Martuzzi, M. Effects of urban green space on environmental health, equity and resilience. In Nature-Based Solutions to Climate Change Adaptation in Urban Areas; Springer: Berlin, Germany, 2017; pp. 187-205.

15. Lee, A.C.; Jordan, H.C.; Horsley, J. Value of urban green spaces in promoting healthy living and wellbeing: Prospects for planning. Risk Manag. Healthc. Policy 2015, 8, 131-137. [CrossRef] [PubMed]

16. Goonetilleke, A.; Yigitcanlar, T.; Ayoko, G.; Egodawatta, P. Sustainable Urban Water Environment: Climate, Pollution and Adaptation; Edward Elgar: Cheltenham, UK, 2014.

17. Rostami, R.; Lamit, H.; Khoshnava, S.M.; Rostami, R.; Rosley, M.S. Sustainable cities and the contribution of historical urban green spaces: A case study of historical persian gardens. Sustainability 2015, 7, 13290-13316. [CrossRef]

18. Bakhshi, M. Natural arteries of Isfahan the give identity to this city. Int. Res. J. Appl. Basic Sci. 2014, 8, 534-539.

19. Gesler, W.J. Healing Places; Rowman and Littlefield: Lanham, MD, USA, 2003.

20. Gesler, W. Lourdes: Healing in a place of pilgrimage. Health Place 1996, 2, 95-105. [CrossRef]

21. Cattell, V.; Dines, N.; Gesler, W.; Curtis, S. Mingling, observing, and lingering: Everyday public spaces and their implications for well-being and social relations. Health Place 2008, 14, 544-561. [CrossRef] [PubMed]

22. Reshadat, S.; Zangeneh, A.; Saeidi, S.; Teimouri, R.; Yigitcanlar, T. Measures of spatial accessibility to health centers: Investigating urban and rural disparities in Kermanshah, Iran. J. Public Health 2018. [CrossRef]

23. Wakefield, S.; McMullan, C. Healing in places of decline: (Re)imagining everyday landscapes in Hamilton, Ontario. Health Place 2005, 11, 299-312. [CrossRef] [PubMed]

24. Smyth, F. Medical geography: Therapeutic places, spaces, and networks. Prog. Hum. Geogr. 2005, $29,488-495$. [CrossRef]

25. Amoly, E.; Dadvand, P.; Forns, J.; López-Vicente, M.; Basagaña, X.; Julvez, J.; Alvarez-Pedrerol, M.; Nieuwenhuijsen, M.J.; Sunyer, J. Green and blue spaces and behavioral development in Barcelona schoolchildren: The BREATHE project. Environ. Health Perspect. 2014, 122, 1351-1358. [CrossRef] [PubMed]

26. Berman, M.G.; Kross, E.; Krpan, K.M.; Askren, M.K.; Burson, A.; Deldin, P.J.; Kaplan, S.; Sherdell, L.; Gotlib, I.H.; Jonides, J. Interacting with nature improves cognition and affect for individuals with depression. J. Affect. Disord. 2012, 140, 300-305. [CrossRef] [PubMed]

27. Nutsford, D.; Pearson, A.L.; Kingham, S. An ecological study investigating the association between access to urban green space and mental health. Public Health 2013, 127, 1005-1011. [CrossRef] [PubMed]

28. Maas, J.; Verheij, R.A.; de Vries, S.; Spreeuwenberg, P.; Schellevis, F.G.; Groenewegen, P.P. Morbidity is related to a green living environment. J. Epidemiol. Community Health 2009, 63. [CrossRef] [PubMed]

29. Pearce, J.; Mitchell, R.; Shortt, N. Place, space, and health inequalities. In Health Inequalities: Critical Perspectives; Oxford University Press: Oxford, UK, 2016; pp. 192-205.

30. Bolund, P.; Hunhammar, S. Ecosystem services in urban areas. Ecol. Econ. 1999, 29, 293-301. [CrossRef]

31. Van Herzele, A.; Wiedemann, T. A monitoring tool for the provision of accessible and attractive urban green spaces. Landsc. Urban Plan. 2003, 63, 109-126. [CrossRef]

32. Lovasi, G.S.; Lemaitre, R.N.; Siscovick, D.S.; Dublin, S.; Bis, J.C.; Lumley, T.; Heckbert, S.R.; Smith, N.L.; Psaty, B.M. Amount of leisure-time physical activity and risk of nonfatal myocardial infarction. Ann. Epidemiol. 2007, 17, 410-416. [CrossRef] [PubMed]

33. James, P.; Tzoulas, K.; Adams, M.D.; Barber, A.; Box, J.; Breuste, J.; Elmqvist, T.; Frith, M.; Gordon, C.; Greening, K.L.; et al. Towards an integrated understanding of green space in the European built environment. Urban For. Urban Green. 2009, 8, 65-75. [CrossRef]

34. Nowak, D.J.; Crane, D.E.; Stevens, J.C. Air pollution removal by urban trees and shrubs in the United States. Urban For. Urban Green. 2006, 4, 115-123. [CrossRef] 
35. Kuo, F.E. Coping with poverty: Impacts of environment and attention in the inner city. Environ. Behav. 2001, 33, 5-34. [CrossRef]

36. Benedict, M.; McMahon, E. Green Infrastructure: Smart Conservation for the 21st Century; Sprawl Watch Clearinghouse: Washington, DC, USA, 2002.

37. Dizdaroglu, D.; Yigitcanlar, T.; Dawes, L. A micro-level indexing model for assessing urban ecosystem sustainability. Smart Sustain. Built Environ. 2012, 1, 291-315. [CrossRef]

38. Yigitcanlar, T. Sustainable Urban and Regional Infrastructure Development: Technologies, Applications and Management: Technologies, Applications and Management; IGI Global: Hersey, PA, USA, 2010.

39. Yigitcanlar, T. Rethinking Sustainable Development: Urban Management, Engineering, and Design; IGI Global: Hersey, PA, USA, 2010.

40. White, M.P.; Alcock, I.; Wheeler, B.W.; Depledge, M.H. Coastal proximity and health: A fixed effects analysis of longitudinal panel data. Health Place 2013, 23, 97-103. [CrossRef] [PubMed]

41. Triguero-Mas, M.; Dadvand, P.; Cirach, M.; Martínez, D.; Medina, A.; Mompart, A.; Basagaña, X.; Gražulevičienè, R.; Nieuwenhuijsen, M.J. Natural outdoor environments and mental and physical health: Relationships and mechanisms. Environ. Int. 2015, 77, 35-41. [CrossRef] [PubMed]

42. Foley, R.; Kistemann, T. Blue space geographies: Enabling health in place. Health Place 2015, 35, 157-165. [CrossRef] [PubMed]

43. Dorn, M.; Laws, G. Social theory, body politics, and medical geography: Extending Kearns's invitation. Prof. Geogr. 1994, 46, 106-110. [CrossRef]

44. Longhurst, R. Fat bodies: Developing geographical research agendas. Prog. Hum. Geogr. 2005, 3, $247-259$. [CrossRef]

45. Wheeler, B.W.; White, M.; Stahl-Timmins, W.; Depledge, M.H. Does living by the coast improve health and wellbeing? Health Place 2012, 18, 1198-1201. [CrossRef] [PubMed]

46. Kistemann, T.; Völker, S.; Lengen, C. Stadtblau-Die Gesundheitliche Bedeutung von Gewässern in Urbanen Raum; Bedeutung von Stadtgrün für Gesundheit und Wohlbefinden; Natur-und Umweltschutz Akademie: Recklinghausen, Germany, 2010; pp. 61-66.

47. Roe, J.J.; Aspinall, P.A. Adolescents' daily activities and the restorative niches that support them. Int. J. Environ. Res. Public Health 2012, 9, 3227-3244. [CrossRef] [PubMed]

48. White, M.P.; Pahl, S.; Ashbullby, K.; Herbert, S.; Depledge, M.H. Feelings of restoration from recent nature visits. J. Environ. Psychol. 2013, 35, 40-51. [CrossRef]

49. Ashbullby, K.J.; Pahl, S.; Webley, P.; White, M.P. The beach as a setting for families' health promotion: A qualitative study with parents and children living in coastal regions in Southwest England. Health Place 2013, 23, 138-147. [CrossRef] [PubMed]

50. Jeon, J.Y.; Lee, P.J.; You, J.; Kang, J. Perceptual assessment of quality of urban soundscapes with combined noise sources and water sounds. J. Acoust. Soc. Am. 2010, 127, 1357-1366. [CrossRef] [PubMed]

51. Coensel, B.D.; Vanwetswinkel, S.; Botteldooren, D. Effects of natural sounds on the perception of road traffic noise. J. Acoust. Soc. Am. 2011, 129, EL148-EL153. [CrossRef] [PubMed]

52. Voelker, S.; Baumeister, H.; Classen, T.; Hornberg, C.; Kistemann, T. Evidence for the temperature-mitigating capacity of urban blue space-A health geographic perspective. Erdkunde 2013, 1, 355-371. [CrossRef]

53. Barton, J.; Pretty, J. What is the best dose of nature and green exercise for improving mental health? A multi-study analysis. Environ. Sci. Technol. 2010, 44, 3947-3955. [CrossRef] [PubMed]

54. Yigitcanlar, T.; Foth, M.; Kamruzzaman, M. Towards post-anthropocentric cities: Reconceptualizing smart cities to evade urban ecocide. J. Urban Technol. 2018. [CrossRef]

55. Haeffner, M.; Jackson-Smith, D.; Buchert, M.; Risley, J. Accessing blue spaces: Social and geographic factors structuring familiarity with, use of, and appreciation of urban waterways. Landsc. Urban Plan. 2017, 167, 136-146. [CrossRef]

56. Corti, L. Clive Seale (1999): The quality of qualitative research. Forum Qual. Sozialforschung/Forum Qual. Soc. Res. 2000, 1, 46.

57. Baum, S.; Kendall, E.; Muenchberger, H.; Gudes, O.; Yigitcanlar, T. Geographical information systems: An effective planning and decision-making platform for community health coalitions in Australia? Health Inf. Manag. J. 2010, 39, 28-33.

58. Flick, U. An Introduction to Qualitative Research; Sage: London, UK, 2014. 
59. Abraham, A.; Sommerhalder, K.; Abel, T. Landscape and well-being: A scoping study on the health-promoting impact of outdoor environments. Int. J. Public Health 2010, 55, 59-69. [CrossRef] [PubMed]

60. Ghalehnoee, M.; Alikhani, M. Evaluation of Isfahan's "Madies" as greenways, with sustainable development approach: A case study of Niasarm Madi. J. Environ. Stud. 2015, 40, 52-54.

61. Bowler, D.E.; Buyung-Ali, L.; Knight, T.M.; Pullin, A.S. Urban greening to cool towns and cities: A systematic review of the empirical evidence. Landsc. Urban Plan. 2010, 97, 147-155. [CrossRef]

62. Hartig, T.; van den Berg, A.E.; Hagerhall, C.M.; Tomalak, M.; Bauer, N.; Hansmann, R.; Ojala, A.; Syngollitou, E.; Carrus, G.; van Herzele, A.; et al. Health benefits of nature experience: Psychological, social and cultural processes. In Forests, Trees and Human Health; Springer: Dordrecht, The Netherlands, 2011; pp. 127-168.

63. Milligan, C.; Gatrell, A.; Bingley, A. 'Cultivating health': Therapeutic landscapes and older people in northern England. Soc. Sci. Med. 2004, 58, 1781-1793. [CrossRef]

64. Sugiyama, T.; Thompson, C.W. Older people's health, outdoor activity and supportiveness of neighbourhood environments. Landsc. Urban Plan. 2007, 83, 168-175. [CrossRef]

65. Francis, M. Control as a dimension of public-space quality. In Public Places and Spaces, Human Behavior and Environment (Advances in Theory and Research); Springer: Boston, MA, USA, 1989; pp. 147-172.

66. Williams, A. Changing geographies of care: Employing the concept of therapeutic landscapes as a framework in examining home space. Soc. Sci. Med. 2002, 55, 141-154. [CrossRef]

67. Lak, A.; Aghamolaei, R.; Azizkhani, E. From segregation to integration of new developments in historic contexts: Rural texture in Iran. J. Settl. Spat. Plan. 2018, 9, 59-66.

68. Mitchell, V. Applying integrated urban water management concepts: A review of Australian experience. Environ. Manag. 2006, 37, 589-605. [CrossRef] [PubMed]

69. Wong, T. Brown, R. The water sensitive city: Principles for practice. Water Sci. Technol. 2009, 60, 673-682. [CrossRef] [PubMed]

70. Sharma, A.; Pezzaniti, D.; Myers, B.; Cook, S.; Tjandraatmadja, G.; Chacko, P.; Chavoshi, S.; Kemp, D.; Leonard, R.; Koth, B.; et al. Water sensitive urban design: An investigation of current systems, implementation drivers, community perceptions and potential to supplement urban water services. Water 2016, 28, 272. [CrossRef]

71. Arbolino, R.; Carlucci, F.; Cirà, A.; Ioppolo, G.; Yigitcanlar, T. Efficiency of the EU regulation on greenhouse gas emissions in Italy: The hierarchical cluster analysis approach. Ecol. Indic. 2017, 81, 115-123. [CrossRef]

72. Arbolino, R.; Carlucci, F.; Simone, L.; Yigitcanlar, T.; Ioppolo, G. The policy diffusion of environmental performance in the European countries. Ecol. Indic. 2018, 89, 130-138. [CrossRef]

73. Kamruzzaman, M.; Deilami, K.; Yigitcanlar, T. Investigating the urban heat island effect of transit-oriented development in Brisbane. J. Transp. Geogr. 2018, 66, 116-124. [CrossRef]

74. Corburn, J. Confronting the challenges in reconnecting urban planning and public health. Am. J. Public Health 2004, 94, 541-546. [CrossRef]

75. Nelson, G.; Hansz, J.A.; Cypher, M.L. The influence of artificial water canals on residential sale prices. Apprais. J. 2005, 73, 167-174.

76. Mahbub, P.; Goonetilleke, A.; Ayoko, G.; Egodawatta, P.; Yigitcanlar, T. Analysis of build-up of heavy metals and volatile organics on urban roads in Gold Coast, Australia. Water Sci. Technol. 2011, 63, 2077-2085. [CrossRef] [PubMed]

77. Sansalone, J.; Buchberger, S. Partitioning and first flush of metals in urban roadway storm water. J. Environ. Eng. 1997, 123, 134-143. [CrossRef]

78. Dur, F.; Yigitcanlar, T.; Bunker, J. A spatial-indexing model for measuring neighbourhood-level land-use and transport integration. Environ. Plan. B Plan. Des. 2014, 41, 792-812. [CrossRef]

79. Yigitcanlar, T.; Kamruzzaman, M.; Teriman, S. Neighborhood sustainability assessment: Evaluating residential development sustainability in a developing country context. Sustainability 2015, 7, 2570-2602. [CrossRef]

80. Fernald, A.; Tidwell, V.; Rivera, J.; Rodríguez, S.; Guldan, S.; Steele, C.; Ochoa, C.; Hurd, B.; Ortiz, M.; Boykin, K.; et al. Modeling sustainability of water, environment, livelihood, and culture in traditional irrigation communities and their linked watersheds. Sustainability 2012, 4, 2998-3022. [CrossRef]

(C) 2018 by the authors. Licensee MDPI, Basel, Switzerland. This article is an open access article distributed under the terms and conditions of the Creative Commons Attribution (CC BY) license (http:/ / creativecommons.org/licenses/by/4.0/). 